\title{
Combining floristic and growth form composition in a gradient- directed vegetation survey of Matjiesrivier Nature Reserve, Western Cape, South Africa
}

\author{
R.G. LECHMERE-OERTEL* and R.M. COWLING**
}

Keywords: biomes, Cederherg, floristic, fynbos, gradsects, growth forms. Matjiesrivier Nature Reserve. Succulent Karoo, survev. Western Cape

ABSTRACT

The floristically complex vegetation of Matjiesrivier Nature Reserve (MNR), which spans the ecotone between the Fynbos and Succulent Karoo Biomes in the eastem Cederberg Mountains. Western Cape. was surveyed using a gradientdirected transect (gradsect). The gradsect was aligned with a top(-)-climatic aridity gradient across MNR. The vegetation was classified using TWINSPAN. based on a combination of floristic and growth form characteristics. and an understanding of the main ecological gradients controlling vegetation distribution. The final classification described seven robust and ecologically meaningful communities that represented a trade-off between statistical rigour and practicality for management. The seven communities were mapped using a geographical information svstem (GIS).

CONTENTS

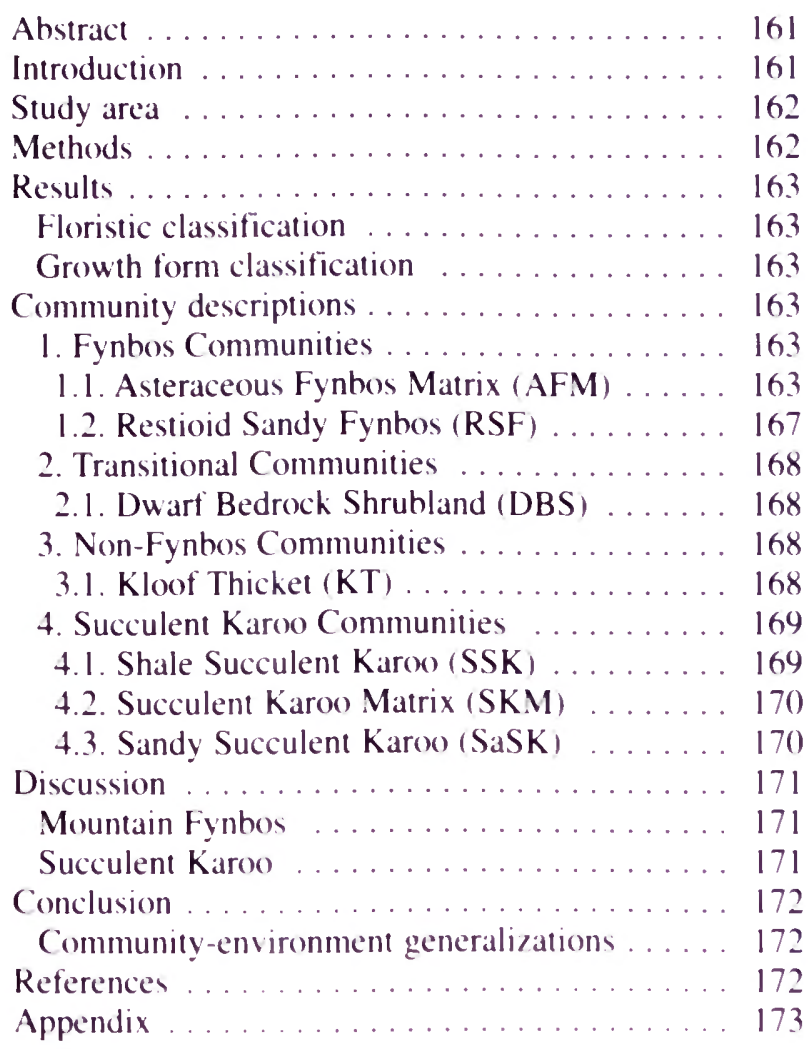

INTRODUCTION

The vegetation in the Fynbos-Succulent Karoo ecotone, Western Cape is structurally and floristically complex. as it comprises elements from three distinct and typically speciose vegetation types (Table I): Mountain Fynbos (Rebelo 1996a). Central Mountain Renosterveld

\footnotetext{
* Department of Zexelogs. University of Port Elizabeth. PO Bos I fox). (x) Port Elizabeth

* Institute for Plant Conservation. Department of Botany. Universits of Cape Toun. Private Bag. 770$)$ Rondebosch. Cape Toun.

MS received $1998-160.1 \%$
}

(Rebelo 1996b) and Lowland Succulent Karoo (Hoffman 1996). Although the Fynbos Biome has received considerable attention in terms of vegetation classification. litthe work has been done in the arid fynbos and Renosterveld of the northwest region of the Fynbos Biome (Cowling et al. 1997) or in the Fynbos-Succulent Karoo ecotone.

This ecotonal vegetation is a mosaic of arid Fynbos. Renosterveld and Succulent Karoo separated out along gradients of moisture, soil conditions and disturbance regime. Fynbos is typically found on fire-prone mesic sites with sandstone-derived soils, Renosterveld on mesic sites with shale-derived soils and Succulent Karoo on fire-free xeric sites, irrespective of soil type. Fire is the driving disturbance in fynbos. imposing an element of stochasticity on the establishment of species assemblages (Cowling et al. 1997). Herbivory and drought are the major disturbances that influence species assemblages in Succulent Karoo (Milton et al. 1997).

TABLE 1.-The major structural differences between the three vege tation types converging at Matjiesrivier Nature Reserve (adapted from Low \& Rehelo 1996)

\begin{tabular}{|c|c|}
\hline Vegetation Type & Major structural characteristics \\
\hline $\begin{array}{l}\text { Asteraceous } \\
\text { Fyntex }\end{array}$ & $\begin{array}{l}\text { A mid-high to tall shrubland characterised by } \\
\text { the presence of three elements: } \\
\text { 1) ericoid shrubs with evergreen. rolled. } \\
\text { slerophyllous and leptophyllous leaves: } \\
\text { 2) restioid reeds with aphyllous and photo- } \\
\text { synthetic stems } \\
\text { 3) proteond shrubs with broad. isobilateral } \\
\text { leaves. }\end{array}$ \\
\hline $\begin{array}{l}\text { Central Mountain } \\
\text { Renosterveld }\end{array}$ & $\begin{array}{l}\text { A low to mid-high shrubland dominated hy } \\
\text { evergreen plants with cupressold and lepto- } \\
\text { phyllous leaves. High proportion of grastes } \\
\text { and geophytes when not overgrazed. Otien } \\
\text { transitional hetween Fyntos and Succulent } \\
\text { Karco. }\end{array}$ \\
\hline $\begin{array}{l}\text { Louland Succulent } \\
\text { Kar(x) }\end{array}$ & $\begin{array}{l}\text { A duarf shrubland dominated by leaf-and } \\
\text { stem-succulent plants. Grasses are relatively } \\
\text { rare }\end{array}$ \\
\hline
\end{tabular}


The juxtaposition of three major vegetation types in a single reserve raises problems for the management and conservation of the flora at MNR. Each vegetation type, particularly succulent karoo and fynbos, needs to be managed separately, as they respond differently to certain management actions such as fire and have different grazing capacities (Van Wilgen et al. 1992; Milton \& Dean 1996). There was thus a need for the vegetation in MNR to be classified into management units, which would allow the application of different management strategies to different vegetation communities. To be meaningful for managers, who may not necessarily have botanical training, the classification needed to be relatively simple and based on easily identifiable structural characters, higher taxa and dominant genera or species.

The aim of this survey was to classify the vegetation of MNR into ecologically meaningful units (communities) that were easily identifiable using simple growth form and floristic characters. These vegetation communities of MNR were mapped within a GIS framework.

\section{STUDY AREA}

Matjiesrivier Nature Reserve ( $\left.32^{\circ} 25^{\prime} \mathrm{S}, 19^{\circ} 17^{\prime} \mathrm{E}\right)$ lies to the east of the Cederberg Mountains, Western Cape. MNR experiences a Mediterranean-type climate with a strong topo-climatic gradient $( \pm 100-300 \mathrm{~mm}$ annual rainfall) superimposed over an abrupt transition from sandy, infertile soils (over Table Mountain Group Sandstone) to clayey, fertile soils (over Bokkeveld Group Shale) (Figure 1). MNR, prior to being purchased for conservation in 1991, was a commercial stock farm for approximately 150 years, with a little arable land in the Matjiesrivier Valley. There are no farm records detailing stocking strategies or fire history. The vegetation on MNR reflects the main environmental gradients of moisture and soil with a gradual transition from Mountain Fynbos to Succulent Karoo from west to east, and a sharp boundary over the transition from Table Mountain Sandstone to Bokkeveld Shale. Patches of Renosterveld are found on mesic shale-derived soils.

\section{METHODS}

The abundance and percentage cover of all perennial plant species with a cover of $>5 \%$ was estimated in 125 .
$10 \times 10 \mathrm{~m}$ sites during the winter of 1996 . The cover and abundance data for each species were combined into nine categories using the Domin scale (Causton 1988). Species occurring in fewer than three sites were removed from the data analyses. Every species was classified into a unique growth form: forb, sedge, grass, restioid, geophyte, leafsucculent shrub, stem-succulent shrub, evergreen shrub and deciduous shrub. The restioids and shrubs were further divided into height classes: dwarf $(<0.25 \mathrm{~m})$, low $(0.25-1.0 \mathrm{~m})$, medium $(1-2 \mathrm{~m})$ and tall $(>2 \mathrm{~m})$. Each growth form represented a functional type with known differences in eco-physiological behaviour (Cowling et al. 1994). The cover data for all species that fell into the same growth form were totaled within each site. Several climatic, topographic and edaphic variables were measured or estimated for each site. The mean and standard deviation of several environmental variables were calculated for all the sites comprising a community.

The sites were positioned through MNR using an approach similar to that employed by gradsect sampling (Gillison \& Brewer 1985; Austin \& Heyligers 1991). Gradsect sampling is the deliberate positioning of transects along the potentially most important environmental gradient in the area. Assuming that plant species or communities are separated along an environmental gradient, positioning sites within a gradsect ensures that the greatest range of vegetation is included in the sampling (Austin \& Heyligers 1991).

A conspicuous environmental gradient at MNR was an eastward increase in aridity that corresponded to an altitudinal gradient from $\pm 1200 \mathrm{~m}$ in the west to \pm 500 $\mathrm{m}$ in the east. Interpolated rainfall data from the Computing Centre for Water Research (CCWR 1996) minute-by-minute rainfall database, supported this observation. The gradsect used to survey the vegetation at MNR was aligned from west to east and corresponded to the main road access. The sampling effort was mostly confined to areas within about one kilometre from the road. The gradsect was further stratified using geology (Sandstone or Shale) and land type (bedrock sheet, sandy plain, gravel pan or other).

The data were analysed using the polythetic classification computer program TWINSPAN (Hill 1979). The default settings were used except for the floristic classification where the five pseudospecies cutoff levels were set

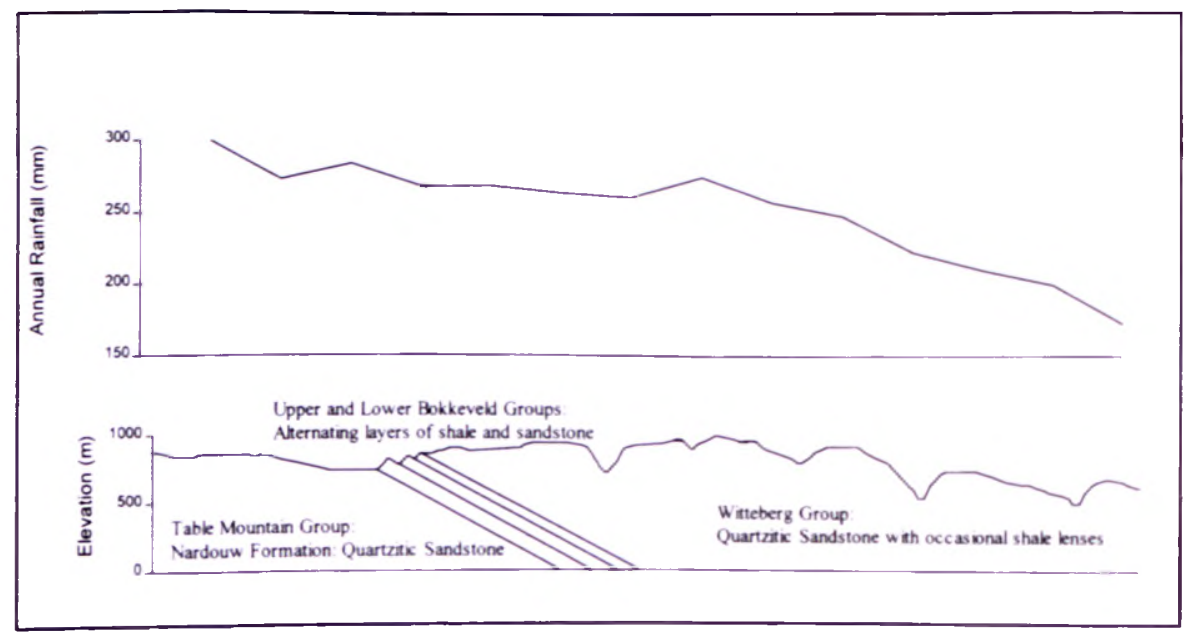

FIGURE 1.-. The west-east aridity gradient superimposed over the geological transition from sandstone to shale. 
at $0,3,5,7,9$ to account for the Domin scale. We initially classified the vegetation using both the floristic and growth form data sets separately and compared the two classifications. Ultimately, the vegetation was classified into communities or management units based on an intuitive combination of the growth form and floristic classifications and field notes made during the survey. In the final classification. we used a combination of obvious growth form characteristics combined with the dominant families, genera or species. Although not strictly objective, this method provided a workable and robust set of communities, which were a satisfactory compromise between ecological meaning and manageability. A map of the vegetation at MNR, based on the communities derived from the classification was prepared using a combination of GIS coverages, aerial photographs and field notes

\section{RESULTS}

\section{Floristic classification}

Seven major communities were derived from the floristic classification (Figure 2). The differential species from TWINSPAN were not always used as the diagnostic species in the final classification. The first division of sites was into fynbos and thicket and succulent karoo. At the second division the succulent karoo sites were divided into two communities based on underlying geology: one located exclusively on shale-derived soils (Shale Succulent Karoo) and the other on sandstone-derived soils. The fynbos sites did not split into meaningful communities at the second division.

At the third level, the succulent karoo sites on shale were divided into two forms ( 1 and 2), with no obviously apparent ecological significance. The succulent karoo sites on sandstone were divided into two communities based on land type. Sandy Succulent Karoo was found on deep sand plains whereas Succulent Karoo Matrix was found on the rocky slopes. The fynbos sites were divided into four communities based on land type. Dwarf Bedrock Shrubland was found on bedrock sheets, Restioid Sandy Fynbos on deep sand plains. Kloof Thicket around large outcrops of rock and Asteraceous Fynbos Matrix on the rocky slopes and cliff tops. Dwarf Bedrock Shrubland. which was not derived in the growth form classification. was included as an important component of the vegetation based on field observations. The communities and their ecological significance are discussed in the community descriptions. A list of all the species names used in the classification, with their authors is given in the appendix.

\section{Growth form classification}

The growth form classification (Figure 3) was fundamentally similar to the floristic classification. and all the communities except Dwarf Bedrock Shrubland were resolved. The differential growth forms at each division of the classification gave some indication of the dominant growth forms characteristic of each community. The initial division of sites was into fynbos and non-fynbos or transitional. At the second division. a small group of sites, which were congruent with the Restioid Sandy
Fynbos in the floristic classification, split off from the fynbos sites. The remaining fynbos sites made up the Asteraceous Fynbos Matrix from the floristic classification. The non-fynbos sites were split into Succulent Karoo and a Fynbos-Succulent Karoo transitional group.

At the third division, the Asteraceous Fynbos Matrix sites were divided into two forms not similar to the two forms in the floristic classification. The group of Succulent Karoo sites remained largely intact except for four sites that split off for no apparent ecological reason. The transitional sites were split into two groups. The sites in the first group were congruent with those of the Kloof Thicket Community in the floristic classification. The sites in the second group were a combination of Shale Succulent Karoo and Asteraceous Fynbos Matrix from the floristic classification and probably represented a transitional zone between these two communities.

At the fourth level of division. further resolution was only obtained by splitting the Succulent Karoo sites into two groups. The one group had sites congruent with Sandy Succulent Karoo whereas the other had sites congruent with Succulent Karoo Matrix in the floristic classification.

\section{COMMUNITY DESCRIPTIONS}

The final classification of the vegetation was made from an intuitive combination of the growth form and floristic classifications. Seven major communities were recognised and are described below according to their growth form and floristic composition. These communities were thought to be ecologically significant and were used as units in the vegetation map (Figure 4).

\section{Fynbos Communities}

Fynbos at MNR is characterised by a few distinct growth forms. families and species. The dominant growth forms are low to medium woody shrubs with leptophyllous and sclerophyllous ericoid leaves, dwarf to tall restioids and dwarf to low sedges. One species that repeatedly came up as an indicator species is Diosma acmaeophylla (Rutaceae). which is a medium to tall evergreen, ericoid shrub. Fynbos communities are restricted to the western half of MNR where rainfall and altitude are relatively high and the soils derived from sandstone. Fynbos communities made up a mosaic in this half of MNR. depending on the land type.

\subsection{Asteraceous Fynbos Matrix (AFM)}

Related communities: Camphell's (1985) Dry Asteraceous Fynbos.

AFM is a heterogeneous community and is more a 'dumping category than a distinct community. Plant cover in the sites is $\pm 40 \%$. A mesic and a xeric form are defined in the floristic classification (Figure 2). The mesic form is the "true" fynbos and the xeric form is transitional from fynbos into succulent karoo 


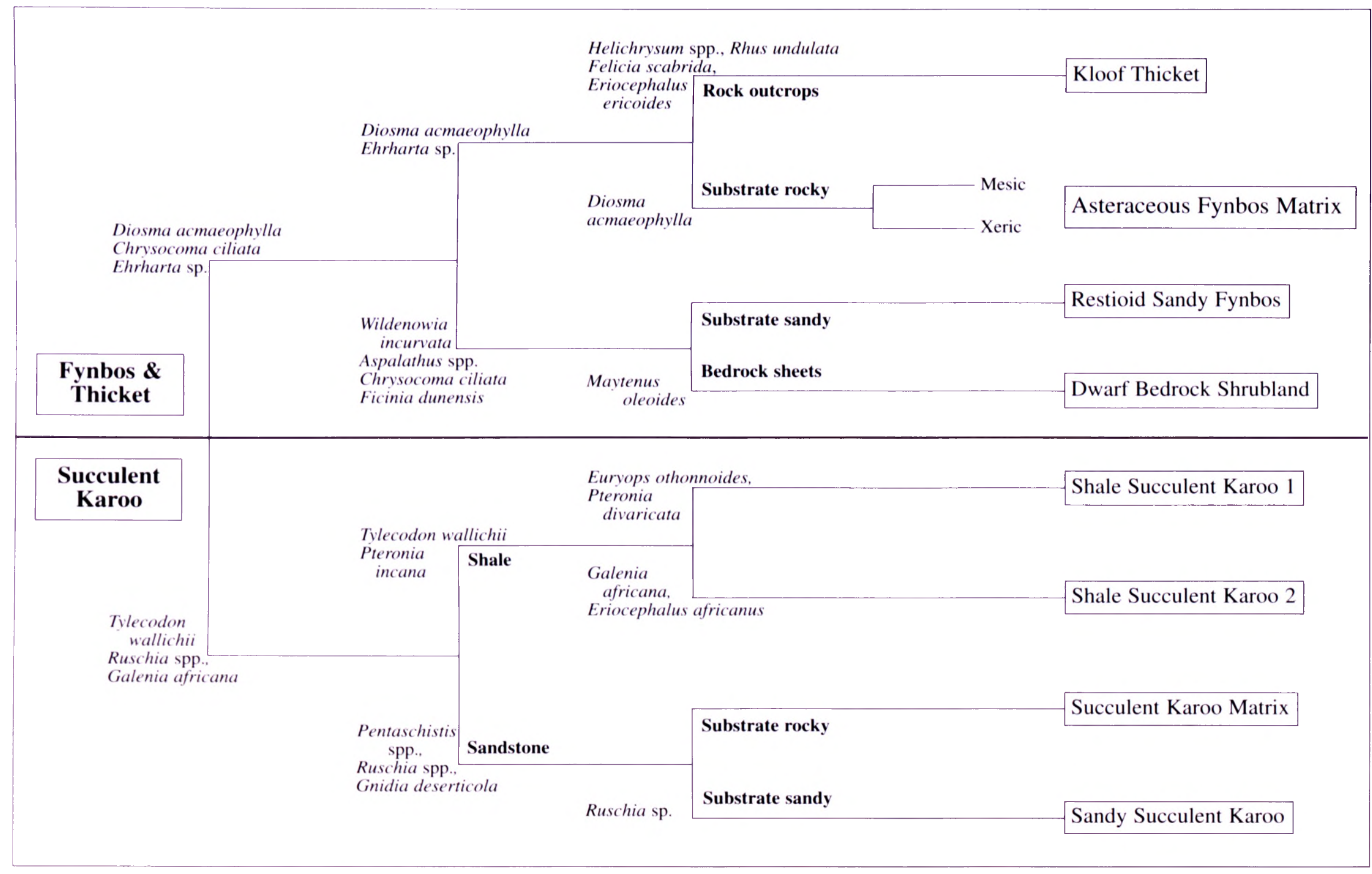

FIGURE 2-The hierarchical classification of the vegetation at Matjiesrivier Nature Reserve based on floristic characters. 


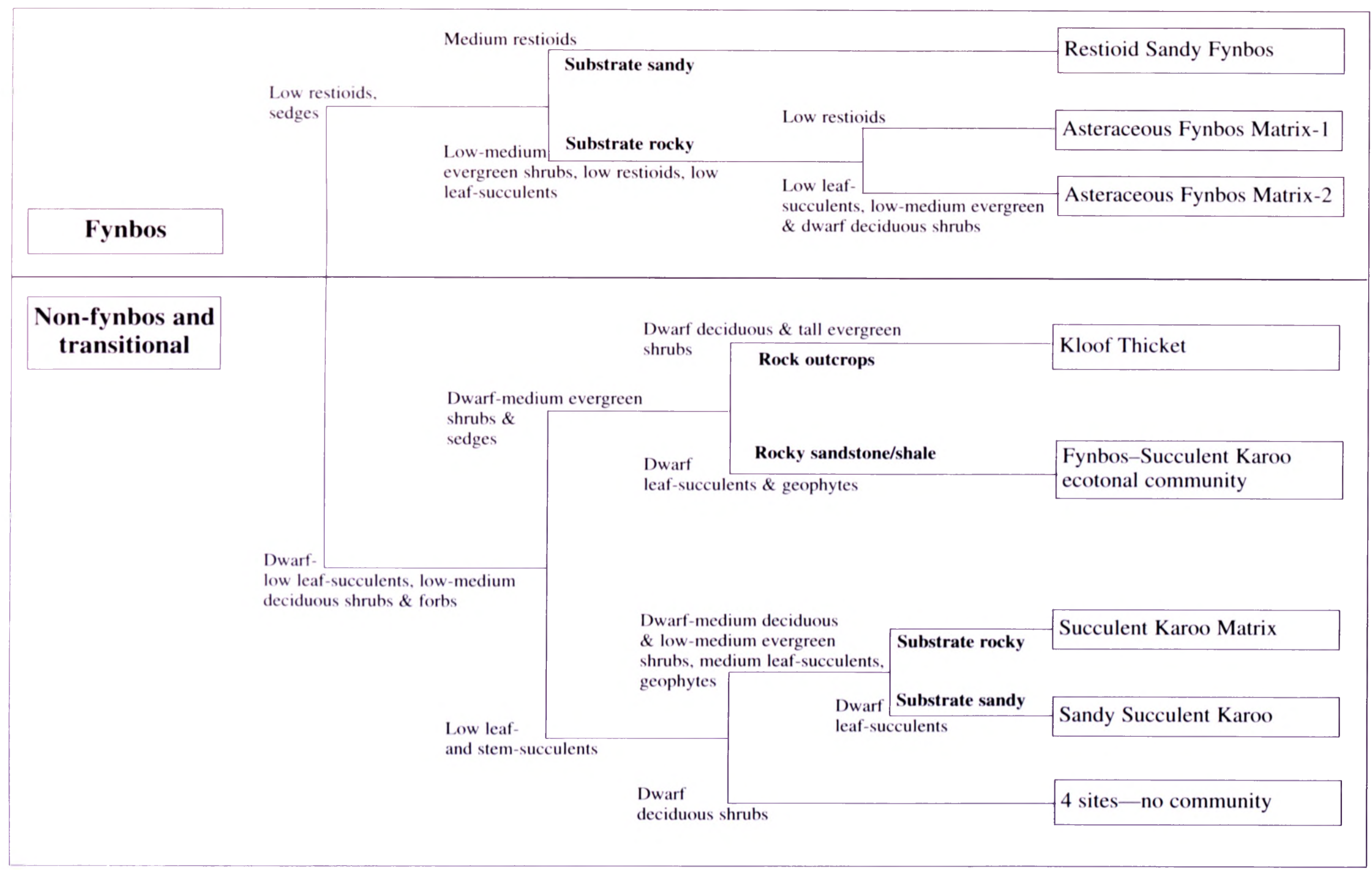




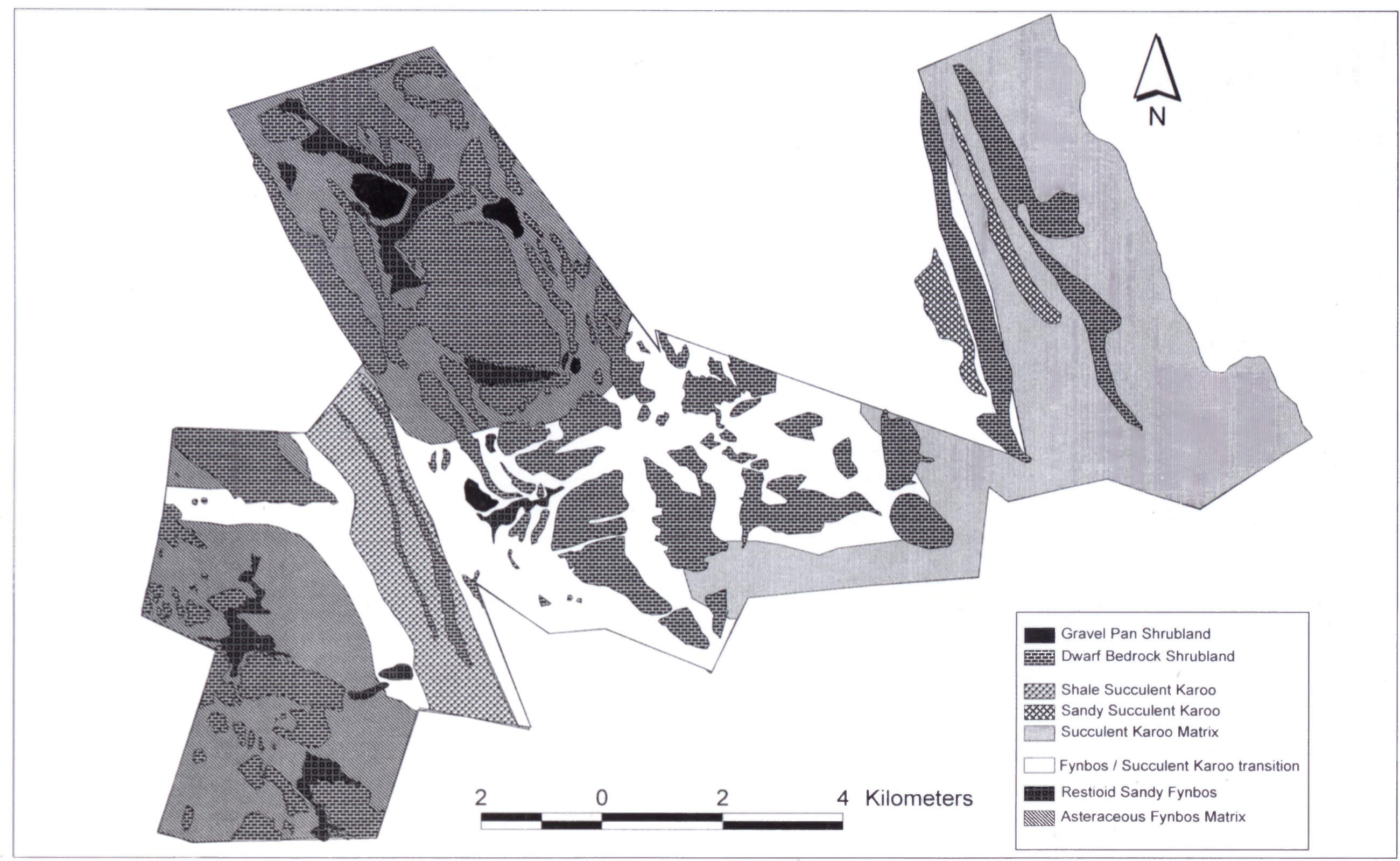




\section{Floristic composition}

All the typical elements of arid mountain fynbos (members of the Asteraceae. Proteaceae. Restionaceae and Poaceae) are present in AFM. Shrubs from the Asteraceae are the most abundant of all the families in the fynbos. Diosma acmaeophvlla is the only indicator species for AFM. However, a number of genera and species are relatively common throughout AFM and are locally abundant in the fine-scale species associations. The mesic and xeric forms of AFM are separated on the basis of dominant genera. The mesic form has a greater proportion of more 'typical' fynbos taxa including: Diosma acmaeophylla. Phylica odorata, Leucadendron pubescens, Aspalathus spp.. Agathosma spp., Stoebe fusca, and Felicia scabrida. Geophytes and members of the Restionaceate (particularly of the genus Cannomois) and Cyperaceae (particularly Ficinia dunensis) dominated the understorey of the mesic form.

The xeric form is characterised by a greater proportion of woody taxa from the Asteraceae including: Eriocephalus africanus, E. ericoides, Pteronia incana, Euryops wageneri, E. othonnoides, Dolichothrix ericoides and Elvtropappus rhinocerotis, and several species of Othonna. Members of the Mesembryanthemaceae and Crassulaceae dominate the field layer. The xeric form of AFM show's affinities to Central Mountain Renosterveld (Rebelo 1996b). However, the relatively high cover of restioids means that this type is classified as a form of fynbos (Campbell 1988).

\section{Structure}

Many of the sites classified as AFM in the floristic classification are classified as transitional with Shale Succulent Karoo in the growth form classification (Figure 2). Low to medium evergreen shrubs, restioids and low leaf-succulent shrubs are the most abundant growth forms in AFM. The vegetation canopy is $0.5-1.5$ $m$ tall with a few taller $(>2 \mathrm{~m})$ evergreen shrubs in particularly mesic sites. In terms of leaf size and form. the leaves of the characteristic shrubs are typically sclerophyllous. leptophyllous and either ericoid or elytropappoid. Low $(0.25-1.0 \mathrm{~m})$ sedges and low to medium $(0.25-2.0 \mathrm{~m})$ restioids occur in dense clumps which are often locally dominant throughout AFM on small sandy patches. Low $(<0.1 \mathrm{~m})$ leat-succulent shrubs make up a significant proportion of the field layer of AFM. especially where the soil is shallow.

\section{Distribution and habitat}

Asteraceous Fynbos Matrix is widely distributed through the western half of MNR (Figure 4). The eastern extreme of xeric AFM (and fynbos in general) is approximately in the middle of MNR (longitude: $19^{\circ} 25^{\prime} \mathrm{E}$ : altitude: $800 \mathrm{~m}$; estimated annual rainfall: $250 \mathrm{~mm}$ ). The boundary between xeric AFM and Succulent Karoo Matrix is characterized by a gradual loss of fynbos elements and a corresponding increase in succulent karoo elements (mostly non-succulent asteraceous shrubs). An increase in aridity, associated with a decrease in altitude. accompanied this transition.
AFM occurs in all topographic positions from flat plateaus and plains to steep slopes, wherever the soil is derived from sandstone or quartzite and where there is a rocky substrate (either as talus or as partially exposed bedrock). Soil conditions are invariably sandy, with a very low clay content and electrical conductivity (Lechmere-Oertel 1998). Isolated patches of AFM are scattered away from the centres of AFM throughout the western half of MNR, in the Fynbos-Succulent Karoo Transition zone (Figure 4). These AFM patches occur at locally mesic sites within the transitional zone. Such sites include many of the high elevation ridges that are more mesic, south-facing slopes and sites where there is precipitation runoff into the soil due to the presence of large rock sheets.

\subsection{Restioid Sandy Fynbos (RSF)}

Related communities: Campbell's (1985) Dry Restioid Fynbos: Taylor's (1996) Community 18 Wildenowia arescens-Thamnochortus platypteris.

RSF is generally low to medium in height $(<2 \mathrm{~m})$ with a canopy layer dominated by either restioids or proteoids. The understorey is either bare or dominated by dwarf $(<0.25 \mathrm{~m})$ graminoids (restioids, grasses and sedges) and leaf-succulent woody shrubs from the Mesembryanthemaceae and Crassulaceae. The percentage cover and average height of plants in RSF appear to depend on moisture availability. In mesic areas there is greater cover (up to $70 \%$ ) of tall restioids and proteoids. whereas the more xeric areas have lower cover $(<40 \%)$ of shorter restioids.

\section{Floristic composition}

Members of the family Restionaceae (restioids) have the greatest cover in RSF. The most conspicuous and locally dominant genera in the Restionaceae are typically Willdenowia. Restio. Thamnochortus, Hypodiscus, Ischyrolepis and Elegia. Large isolated individuals (up to $2 \times 2 \mathrm{~m}$ ) from the genus Willdenowia (mostly Willdenowia incurvata) are scattered through RSF. Some of the patches of RSF are also characterised by the abundance (>10\%) of Leucadendron brunioides var. brunioides (Proteaceae) or other Leucadendron species.

Depending on the apparent moisture availability. there is considerable variation in the understorey of RSF. Grass taxa. particularly the genera Pentaschistis and Ehrharta, are more apparent in the understorey of the xeric areas. There is also an increase in the proportion of mesembs and crassulas in the understorey with increasing aridity. In mesic areas, sedges. notably of the genera Ficinia (mostly Ficinia dunensis) and Tetraria replace the grasses and shrubs in the understorey. Geophytes and annual forbs are also quite common.

There is a distinct form of RSF that has a considerably shomer canopy than the other patches of RSF. and is dominated by Ischvrolepis unispicatus ( $>40 \%$ cover) and Elvropappus rhinocerotis (Asteraceae). This form of RSF only occurs where there is a high cover of small $(<0.05 \mathrm{~m})$ pebbles scattered on or near the surface of the 
sand. These pebbles were possibly derived from the erosion of an ancient Tertiary surface (Taljaard 1949: Peter Holmes pers. comm.).

\section{Structure}

In terms of structure, RSF is quite uniform, with the biggest variation being attributable to differences in height of the canopy. The dominant growth forms in RSF are medium to tall restioids and medium to short sedges and grasses. In a few patches there are very tall proteoid shrubs: otherwise there are few woody shrubs typical of AFM.

\section{Distribution and habitat}

Restioid Sandy Fynbos is found exclusively on patches of deep sand throughout the western half of MNR. The orange or white sand is probably of aeolian origin. There are several large areas of deep sands in the western half of MNR and all of these are covered by RSF (Figure 4). The patches of RSF form islands within the fynbos matrix and have many elements in common with AFM. The sand patches are often interspersed with large sandstone outcrops and bedrock sheets, which harbour Kloof Thicket and Dwarf Bedrock Shrubland Communities.

\section{Transitional Communities}

\subsection{Dwarf Bedrock Shrubland (DBS)}

Related communities: Taylor's (1996) Communities 5.6 \& 7 .

Dwarf Bedrock Shrubland is represented by only two sites in the floristic classification and is not defined as a community in the growth form classification. DBS is included as a distinct community because, based on field observations, it appears to be an important component of the vegetation that may harbour rare or endemic species. Typically, there is a very low cover of vegetation on the sheetrock, as there are only a limited number of cracks and erosion hollows where enough soil can collect to support woody shrubs. The limited soil volume available to most of the shrubs has resulted in stunted growth. Individuals of species which are typically medium to tall in more suitable habitats, remain at $<0.5 \mathrm{~m}$. with only their thick and twisted stems testifying to their age.

\section{Floristic composition}

In mesic areas. DBS is characterised by stunted ericoid, sclerophyllous members of the Ericaceae. Proteaceae and Rhamnaceae. Three species: Erica maximiliani, Protea glabra and Phylica buxifolia, are particularly conspicuous on bedrock sheets throughout the western half of MNR. Large individuals of $P$. glabra (up to $5 \mathrm{~m}$ high), with roots penetrating deep into cracks in the bedrock. are quite common up to the extreme eastern boundary of the fynbos/succulent karoo transition. The dominant species in DBS (based on abundance, as there was never a high cover of vegetation) depend on the surrounding vegetation
Towards the arid east of MNR, taxa common in succulent karoo increase relative to the fynbos taxa. Even within the fynbos matrix there are small populations of members of the Mesembryanthemaceae (Ruschia, Lampranthus, Conophytum) and Crassulaceae (Crassula, Tylecodon) that are able to survive the harsh. xeric conditions of the shallow soil.

\section{Structure}

DBS is structurally diverse and combines typical fynbos and succulent karoo growth forms. Ericoid. sclerophyllous and dwarf leaf-succulent shrubs are found together, which is why DBS is considered as transitional and does not arise as a distinct community in the grow th form classification.

\section{Distribution and habitat}

As the name suggests, DBS is confined to the surfaces of the large sheetrock outcrops that occur throughout MNR (Figure 4). The sheetrock is exposed sandstone or quartzite bedding planes that are typically flat. There are few occurrences of exposed sheets of horizontal shale strata at MNR for comparison between geological groups. The surfaces of the bedrock sheets are typically eroded into channels. crevices and depressions where enough soil and organic matter collects to provide microsites for the growth of woody plants. The depth of the crack (and thus soil) appears to dictate the type and structure of plants that can grow there.

The rocky habitat presents two extremes of water availability to plants that survive on them. During the dry summer season, the exposed sheetrock is exceptionally xeric as there is little soil to act as a reservoir for moisture. During the wet season, the depressions in a sheetrock have an over-abundance of water due to the very high runoff and may become waterlogged. Plants are unable, in most cases, to penetrate subsurface water unless the rock crack in which they are growing is deep enough (as is the case for $P$. glabra). Thus the plants living in rock cracks must be able to survive extended periods of extreme drought during summer, very wet conditions during winter, and rapid changes between a state of moist soil and dry soil.

\section{Non-Fynbos Communities}

\subsection{Kloof Thicket (KT)}

Related communities: Campbell's (1985) Forest and Thicket; Taylor's (1996) Community 4. Olea europaea subsp. africana-Myrsine africana on sand flats and mesic screes.

Kloof Thicket is confined to locally mesic habitats between large rock outcrops. The vegetation canopy is tall to very tall ( $>2 \mathrm{~m}$ ) and cover is high compared to the surrounding fynbos matrix. The floristic composition of $\mathrm{KT}$ is derived from a combination of typical subtropical thicket shrubs and a number of typical fynbos shrubs. The restioid and proteoid growth forms are mostly absent from KT 


\section{Floristic composition}

Kloof Thicket appears in the floristic classification as a subset of fynbos, with Rhus undulata as a differential species. Other thicket species, which we observed as common in KT (but are not apparent in the floristic classification). included Mavtenus oleioides and Dodonaea angustifolia. Depending on the location of the rock outcrop, there are several other woody shrub species more typical of fynbos or the transition from fynbos into succulent karoo such as Diosma acmaeophylla, Phylica buxifolia, Pteronia spp.. Eriocephalus ericoides and Helichrysum spp.

\section{Structure}

Kloof Thicket is structurally easy to identify. It is characterised by tall $(>2 \mathrm{~m}$ ) woody shrubs with large (mesophyllous) evergreen leaves. and by a lack of the restioid and proteoid growth forms. Forbs, ferns and deciduous dwarf shrubs are characteristic of the understorey.

\section{Distribution and habitat}

Kloof Thicket is typically found between the large sandstone outcrops that are dotted through the western half of MNR. These thicket clumps are restricted to the higher rainfall areas of MNR and become less frequent with increasing aridity. KT occurs on patches of shallow aeolian sand trapped between the large outcrops. There is probably considerable runoff from the outcrops during precipitation and thus the soil around the edge of the outcrops receives more effective precipitation than the surrounding vegetation.

The protected nature of the KT sites, which are hemmed in by large outcrops of sandstone, suggests that they are fire refuges. Fire is believed to be a factor that maintains the boundary between fynbos and thicket (Cowling \& Holmes 1992) and it is possible that infrequent fires restrict KT into fire refugia.

\section{Succulent Karoo Communities}

Succulent Karoo sites are separated from fynbos sites on the basis of a number of floristic and growth form characteristics. The main Succulent Karoo families at MNR include the Mesembryanthemaceae. Asteraceae and Crassulaceac. The abundance of leaf-and stem-succulent and deciduous shrubs, and the absence of evergreen leptophyllous shrubs with ericoid leaves. are probably the most important growth form features.

\section{I. Shale Succulent Karoo (SSK)}

Related communities: Campbell's (1985) Succulent Shrubland.

SSK is exclusively confined to a band of exposed shale strata from the Bokkeveld Group. Deciduous shrubs from the Asteraceac. stem-succulent species from Euphorbia. and leaf-and stem-succulent members of the
Mesembryanthemaceae and Crassulaceae dominate SSK. The vegetation in SSK is relatively sparse, with less than $30 \%$ cover and with a canopy height of about one metre. The understorey is also typically sparse, comprising dwarf leaf- and stem-succulent shrubs and many annual ferns, forbs and geophytes.

\section{Floristic classification}

Two differential species. Tylocodon wallichii (Crassulaceae) and Pteronia incana (Asteraceae) are characteristic of SSK in the floristic classification. Other genera from the Asteraceae that are particularly abundant in SSK included Eurvops, Pteronia and Eriocephalus. Pteronia divaricata, Galenia africana. Eriocephalus africanus and $E$. ericoides are most abundant. Large individuals of Euphorbia mauritanica and Tylecodon paniculatus are dotted throughout the community. Although these individuals do not account for a large proportion of the cover, they are a conspicuous and diagnostic feature of SSK. Species diversity in SSK is relatively low compared to the other succulent karoo communities.

Two formations, SSK-1 and SSK-2, are derived in the floristic classification based on the presence of Euryops othonnoides and Pteronia divaricata in SSK-1 and Galenia africana and Eriocephalus africanus in SSK-2. The separation of SSK sites into these formations did not make ecological sense, therefore. SSK was mapped as a single management unit.

'Heuweltjies' or mima-like earth mounds (Knight et al. 1989: Moore \& Picker 1991) are quite common throughout SSK. These mounds are about $0.1-0.5 \mathrm{~m}$ high and $\pm 2-10 \mathrm{~m}$ diam. 'Heuweltiies' differ from the surroundings in terms of soil nutrient. organic matter and moisture status (Milton et al. 1997) and those at MNR support "islands" of vegetation that are noticeably different from the surrounding matrix vegetation. We only sampled three sites on these "heuwelijies". In both the floristic and growth form classifications these sites are assigned to SSK-2. with two characteristic species: Pteronia divaricata and Tylecodon paniculatus.

\section{Structure}

There is no distinct group of sites in the growth form classification that corresponds to the SSK sites in the floristic classification. There is considerable overlap between AFM and SSK and thus, in the growth form classification. SSK appears to be part of a transitional community from fynbos into succulent karoo. This is not surprising considering that most of the growth forms found along the shale band are also found in the fynbos/succulent karoo transition. It is only the charismatic and conspicuous growth forms such as the large stemand leaf-succulents (Tylecodon paniculata and Euphorbia mauritanica) which cause the vegetation on the shale band to look different to the surrounding matrix.

\section{Distribution and habitat}

SSK is found exclusively on the bands of shale and sandstone from the Bokkeveld Group that are exposed 
along their bedding planes near the homestead at MNR (Figure 4). These alternating layers of shale and sandstone give rise to a series of parallel north-south orientated ridges of sandstone and valleys of shale. The shale bedrock is exposed in many places and there is often an overburden of sandstone debris on the slopes from the sandstone ridges. The soil on these slopes is dark brown and has a relatively high proportion of silt and clay, giving rise to a fine-textured loam compared to the surrounding sandstone-derived sands. It is these fine-textured soils which are thought to increase the effect of summer drought on the vegetation, resulting in the occurrence of more succulent karoo taxa compared to the surrounding matrix vegetation (Lechmere-Oertel 1998).

The succulent karoo vegetation growing on gravel patches is also classified as SSK. There is another localised occurrence of shale in MNR. on a south-facing slope in the middle of the Matjiesrivier Gorge. There is extensive folding of the rock strata at this point, and the river has exposed an anticline of Bokkeveld Group Shale beneath the Witteberg Group Sandstone. The vegetation on this shale is dominated by dwarf shrubs (mostly Pteronia spp.). leaf-succulent mesembs and the stemsucculent Euphorbia hamata. There is a very low total cover: probably because the surface is unstable with almost no soil (steep slope and gravelly shale soil which must have had a very high rate of erosion).

The proximity of the Bokkeveld Group ridges and valleys to the homestead and perennial water (the Matjiesrivier) suggests that the SSK community would have been under considerable grazing pressure during the \pm 200 years MNR was a stock farm. Thus the current vegetation and community description is unlikely to reflect what the vegetation would be like in ungrazed conditions.

\subsection{Succulent Karoo Matrix (SKM}

Related communities: a xeric version of Campbell's (1985) Succulent Shrubland that occurs on quartzitic soils.

The most distinguishing feature of SKM is the dominance of leaf-succulent members of the Mesembryanthemaceae and Crassulaceae. both in terms of relative cover in the vegetation and species diversity. The vegetation in SKM is generally less than one metre high and total vegetation cover relatively low $(<30 \%)$. As in AFM, there are two forms within SKM, which reflect the transition from fynbos into succulent karoo. One form occurs in the arid part of the transitional zone and has a combination of typical succulent karoo and fynbos taxa and growth forms. The other form, which occurs in the extreme arid part of MNR is "proper' succulent karoo with very few fynbos elements. These forms comprise an intricate matrix, depending on local environmental conditions that influence water availability, and are not mappable as separate units.

\section{Floristic composition}

Numerous members of the Mesembryanthemaceae and Crassulaceac dominate SKM. There is high species rich- ness in these two families in SKM. which is expected. considering that the succulent karoo is the centre of diversity for these families (Milton et al. 1997). In the floristic classification. two Ruschia species, the grass genus Pentaschistis and the shrub Gnidia deserticola (Thymelaeaceae) are differential taxa for SKM (Figure 2).

In the transitional form of SKM. shrub genera from the Asteraceae. particularly Pteronia. Eriocephalus and Elytropappus, are most common. There are also a number of fynbos taxa present wherever there is enough moisture, such as on south-facing slopes. A number of other conspicuous species such as Euphorbia hamata. $E$. mauritanica. Tylecodon paniculatus and Hoplophyllum spinosa are distributed sparsely through the arid part of the transitional formation.

The 'true' SKM form is almost totally dominated by members of the Mesembryanthemaceae and Crassulaceae and there are few shrubs from other families (Gnidia deserticola is a notable exception as a locally dominant species). Two very common genera from the Mesembryanthemaceae found in SKM are Ruschia and Lampranthus.

\section{Structure}

Dwarf to low leaf-succulent woody shrubs dominate the vegetation in SKM, increasing relative to the nonsucculent shrubs along the aridity gradient. In the "true" SKM form there are few typical fynbos growth forms such as evergreen ericoid shrubs. Medium-height leafsucculent shrubs, geophytes, grasses and deciduous dwarf shrubs are differential growth forms for this formation. In the "transitional' form. low to medium evergreen shrubs, growth forms more typical of the fynbos communities, are differential. The transitional forms reflect a change from evergreen to deciduous and an increase in leaf succulence.

\section{Distribution and habitat}

SKM occurs in the eastern half of MNR (Figure 4). There is a gradual transition from Fynbos into Succulent Karoo marked by an increase in the appearance of typical karroid elements with increasing aridity and a corresponding loss of fynbos elements. SKM occurs in the fynbos part of the transitional zone wherever there is localised aridity. Examples of this include the steep slopes of the Matjiesrivier (jorge and its tributaries in the western half of MNR. The 'true' SKM form is found in the eastern extreme of MNR. near the Doring River.

\subsection{Sandy Succulent Karoo ( $\mathrm{SaSK}$ )}

\section{Related communities: none}

SaSk is the karroid equivalent of Restioid Sandy Fynbos on arid sites. SaSK generally has a sparse cover of vegetation with large spaces between the individual plants. The canopy height is generally less than $0.5 \mathrm{~m}$ and there are few understorey species. The vegetation is quite patchy with relatively dense monospecific populations of several species occurring repeatedly through the 
landscape. In total. SaSK comprises a relatively small area of MNR, and is confined largely to a single valley floor in the eastern part (Figure 3).

\section{Floristic composition}

SaSK is characterised by locally dense populations of Ruschia spp.. Euphorbia deccusata and Zygophyllum retrofractum. Perennial grasses such as Stipagrostis namaquensis are also common except near the old kraal sites, which are dotted through the landscape. Very infrequent patches of Willdenowia incurvata occur in locally mesic areas of deep sand.

\section{Structure}

SaSk is characterised by localised patches of dwarf leaf-succulent or fleshy-leaved shrubs and stem-succulent, aphyllous plants. Grasses are common. and form relatively dense stands except around the old kraal sites. In the more mesic sites of SaSK. localized patches of low to medium restioids occur.

\section{Distribution and habitat}

Sandy Succulent Karoo is found exclusively on deep sands within the karoo matrix in the eastern part of MNR (Figure 4), where the yellow soil is generally deeper than $1.2 \mathrm{~m}$ and there is a very low surface cover of rocks. The sandy soil appears to be well drained and is probably of aeolian origin. similar to the patches in the fynbos matrix.

\section{DISCUSSION}

\section{Mountain Finbos}

Campbell (1985) classified the mountain vegetation of the Fynbos Biome. including the Cederberg Mountains that lie just to the west of MNR. He used a combination of structural characteristics and higher taxa (families) to derive four major vegetation categories: three non-fynbos and one fynbos. Within each category. he described a number of communities. We only discuss those communities that are relevant to the vegetation at MNR.

Forest and Thicket is characterized by a high cover of large shrubs or trees with leaves other than leptophylls. In MNR. this community is usually found within the fynbos matrix at sites that receive runoff from rocky out crops and appear to be protected from fire. Karroid and Renoster shrubland occur over a large part of MNR where the annual rainfall is too low to support fynbos. or where soil conditions result in a pronounced summer aridity (Cowling \& Holmes 1992: Cowling e't al. 1997: Lechmere-Oenel \& Cowling 1999). Dry Asteraceous Fynbos is found on the rocky slopes and Dry Restioid Fynbos on the sand plains. Dry Asteraceous Fynbos is a xeric form of asteraceous fynbos (Table 1 ) characterized by evergreen ericoid shrubs. mainly members of the family Asteraceae, and by a low occurrence of restioids. Dry Restiond Fynbos is characterized by the dominance of restioids and other graminoids, and the relatively low occurrence of ericoid shrubs.

Using floristic characters. Taylor (1996) classified the vegetation of the northern Cederberg Mountains into 26 communities. The only non-fynbos community identified was thicket, and no succulent karoo or renoster shrubland was encountered. Considering that this classification covers a centre of diversity for mountain fynbos, it is not surprising that Taylor (1996) derived so many communities. However, many of his communities cannot be treated as management units as they form part of a complex mosaic that would not be practical to resolve and map for management purposes.

The classification of vegetation in other regions of the Fynbos Biome has received attention from a number of authors. However, because these surveys were carried out at different scales and due to the high turnover in species between regions (gamma diversity) (Bond 1981). we have not referred to these studies in any detail. Cowling \& Holmes (1992) and Cowling et al. (1997) provide good reviews of these phytosociological studies.

\section{Succulent Karoo}

Little work has been done on classifying succulent karoo vegetation. partly because of taxonomic problems in the dominant family, the Mesembryanthemaceae (Hilton-Taylor 1987). Milton (1978) classified the vegetation at Andriesgrond near Clanwilliam, which is on the western side of the Cederberg $(60 \mathrm{~km}$ northwest of MNR). Ten communities, including succulent and broken karoo. were classified. based on floristic and environmental characteristics. However. none of these communities were found at MNR, although there were definitely karroid elements common to both areas. Lane (1978) briefly surveyed the Tanqua/Doorn Karoo using structural characters and derived four communities separated along a moisture gradient. Snijman \& Perry (1987) described the flora of the Nieuwoudtville Wild Flower Reserve that lies on the ecotone between Mountain Fynbos and karroid shrublands. Their survey. however. did not produce any communities that were apparent at MNR. probably because the Nieuwoudtville Reserve lies on dolerite. which gives rise to soil very different from shale- or sandstone-derived soils.

Cowling \& Holmes (1992) and Taylor (1996) provide good summaries of the comparative benefits of a floristic and structural approach to vegetation surveys. Floristic-based methods. which require relatively detailed knowledge of the flora. are more appropriate for long-term management including the conservation of rare and endemic species. They are also more applicable to smaller areas. Structure-based methods are more useful for experimental and autecological studies. which require a detailed record of shon-term changes in the vegetation (e.g. establishing how structural traits vary along resource and nutrient gradients). Structure-based methods. being quicker to use than floristic-based methods. are also more appropriate for surveying extensive areas of tloristically complex vegetation such as fynbos and succulent kar(o). expecially considering time and financial constraints 
The main aim of vegetation classification is to simplify the vegetation into robust units that are recognizable and repeatable through the landscape. Mapping the natural resources benefits nature conservation because the landscape is divided into homogenous units that can be used as a basis for management planning (Pressy \& Bedward 1991). The vegetation at MNR is difficult to classify phytosociologically because it comprises a complex mosaic of communities at a fine scale, which would be impossible to map or treat as management units. Therefore it was necessary to design a classification system for management purposes that overlooked the finescale complexity and defined more pragmatic communities that were both mappable and meaningful for management (Pressy \& Bedward 1991). It is, however, still important to recognise the fine-scale mosaic of communities particularly in terms of conserving species diversity (Campbell 1985).

\section{CONCLUSION}

\section{Community-environment generalizations}

The fynbos communities are confined to the west of MNR. which is generally higher in altitude, and thus cooler, and receives more precipitation. Asteraceous Fynbos Matrix. which occurs on all the rocky talus slopes and areas of partially exposed bedrock. covers most of this mesic area. Within the fynbos matrix, the other fynbos communities are separated according to land type. The deep sandy soils on the flat plains support RSF. Fire-protected and mesic outcrops of sandstone support Kloof Thicket with its tall shrubs and trees that typically have mesophyllous evergreen leaves. The rocky outcrops and exposed sheetrock support a combination of stunted fynbos shrubs and leaf-succulent shrubs with Succulent Karoo affinity that are confined to growing wherever enough soil has collected.

Moving eastward along the aridity gradient, there is a gradual transition from fynbos into succulent karoo. This transition is characterized by a slow turnover of growth forms and species from leptophyllous and sclerophyllous fynbos shrubs to leaf-succulent dwarf shrubs, and by the loss of the restioid growth form. The transitional zone between fynbos and succulent karoo is indistinct. There are many areas where fynbos and succulent karoo elements extend deep into the other, in response to localised moisture gradients caused by geological or topographic features such as the Matjiesrivier Gorge. The steep northfacing slopes of the Matjiesrivier Gorge. which represent a relatively arid environment, give rise to a corridor of succulent karoo deep into the fynbos side of the transitional zone.

By combining the differential species from both the growth form and floristic classifications with personal notes made during the field trips, we believe that the communities derived during this survey are ecologically meaningful and will have use in management planning. The communities were easily identifiable by a few key species, simple growth form groups and knowledge of the different land types. Thus the communities fulfil the desired characteristics of being easily identifiable. eco- logically meaningful and useful for mapping and management.

\section{REFERENCES}

ARNOLD. T.H. \& DE WET. B.C. 1993. Plants of southern Africa: names and distributions. Memoirs of the Botanical Suney of South Africa No. 62.

AUSTIN, M.P. \& HEYLIGERS, P.C. 1991. New approach to vegetation survey design: gradsect sampling. In C.R. Margules \& M.P. Austin. Nature conservation: cost effective biological surveys and data analysis. CSIR(), Australia.

BOND. P. \& GOLDBLATT. P. 1984. Plants of the Cape Flora. A descriptive catalogue. South African Journal of Botany. Suppl. Vol. 13.

BOND. W.J. 1981. Vegetation gradients in the southern Cape mountains. M.Sc. thesis, University of Cape Town.

BRUMMITT. R.K. \& POWELL. C.E. (eds). 1992. Authors of plant names. Royal Botanic Gardens. Kew

CAMPBELL. B.M. 1985. A classification of the mountain vegetation of the Fynbos Biome. Memoirs of the Botanical Survey of South Africa No. 50

CAMPBELL. B.M. 1988. Plant form in the mountains of the Cape. South Africa. Journal of Ecology 76: 637-653

CAUSTON, D.R. 1988. Introduction to vegetation analysis, principles, practice and interpretation. Unwin Hyman. London.

CCWR 1996. Computing Centre for Water Research. University of Natal, Pietermaritzburg. KwaZulu-Natal.

COWLING. R.M. \& HOLMES. P.M. 1992. Flora and vegetation. In R.M. Cowling. The ecology of fynhos: nutrients, fire and diversitv, Oxford University Press. Cape Town.

COWLING. R.M. ESLER. K.J., MIDGLEY, G.F. \& HONIG, M.A. 1994. Plant functional diversity, species diversity and climate in arid and semi-arid southern Africa. Journal of Arid Environments 27: 141-158.

COWLING. R.M. RICHARDSON. D.M. \& MUSTART, P.J. 1997. Fynbos. In R.M. Cowling. D.M. Richardson \& S.M. Pierce. The vegetation of southern Africa. Cambridge University Press. Cambridge.

FORRESTER. J. 1988. Fire in the Karoo National Gardens floral reserve. Veld \& Flora 74: 5.

GILLISON. A.N. \& BREWER. K.R.W. 1985. The use of gradient directed transects or gradsects in natural resource surveys. Journal of Environmental Management 20: 103-127.

HILL, M.O. 1973. Reciprocal averaging: an eigenvector method of ordination. Journal of Ecology 61 : 237-249.

HILL. M.O. 1979. TWINSPAN: a FORTRAN program for arranging multivariate data in an ordered wo-way fable by classification of the individuals and attributes. Comell University. Ithaca. New York

HILTON-TAYLOR, C. 1987. Phytogeography and origins of the Karoo flora. In R.M. Cowling \& P.W. Roux. The karoo biome: a preliminan sinthesis. Part 2: vegetation and histors. South African National Scientific Programmes Report No.142. CSIR. Pretoria.

HOFFMAN, T. 1996. Lowland Succulent Karoo. In A.B. Low \& A.G. Rebelo, Vegetation of South Africa. Le'sotho and Swaziland. Department of Environmental Affairs and Tourism. Pretoria.

KNIGHT. R.S., REBELO. A.G. \& SIEGFRIED. W.R 1989. Plant assemblages on Mima-like earth mounds in the Clanwilliam District. South Africa. South African Journal of Botany 55 $465-472$

L.NE. S. 1978. An ecological study of the Tanqua/Dorn Karoo hased on a structural-physiognomic survey. South African Archaeslogical Bulletin 33: 128-133

LECHMERE-OERTEL. R.G. 1998. The environmental determinants of the finbos/succulent karoo boundary in Matjiesriver Nature Resene, Western Cape. MSc. thesis, University of Cape Toun.

LECHMERE-OERTEL. R.G. \& COWLING. R.M 1999. Predicting the distribution of fynbes and succulent kar(x) boundaries and plant communities using generalised linear models and GIS South African Journal of Botani $65: 89$ 96

LOW. A.B. \& REBELO. A.(i. (cds). 1996 . Vegetation of South Africa. Lesotho and Swaziland Department of Environmental Affairs \& Tourism. Pretoria

MII.TON. S.J. 1978. Plant communistes of the' Andriesgrond. Clanwilliam District. Hahitat Working Group. Bolus Herharium. University of Cape Town. Unpublished. 
MILTON. S.J. \& DEAN. W.R.J. 1996. Karoo veld: ecology and management. Agricultural Research Council, Range and Forage Institute. Lynn East, Pretoria.

MILTON, S.J., YEATON, R.W.E., DEAN. W.R.J. \& VLOK. J.H.J 1997. Succulent Karoo. In R.M. Cowling. D.M. Richardson \& S.M. Pierce, The vegetation of southern Africa. Cambridge University Press, Cambridge.

MOORE. \& PICKER. 1991. Heuweltjies (earth mounds) in the Clanwilliam District. Cape Province. South Africa: 4000 -year-old termite nests. Oecologia 86: $424-430$.

PRESSY. R.L. \& BEDWARD. M. 1991. Mapping the environment at different scales: benefits and costs for nature conservation. In C.R. Margules \& M.P. Austin. Nature consenation: cost effective biological surveys and data analysis. CSIRO. Australia.

REBELO. A.G. 1996a. Central Mountain Renosterveld. In A.B. Low \& A.G. Rebelo, Vegetation of South Africa. Lesotho and
Swaziland. Department of Environmental Affairs and Tourism. Pretoria.

REBELO. A.G. 1996b. Mountain Fynbos. In A.B. Low \& A.G. Rebelo, Vegetation of South Africa, Lesotho and Swaziland. Department of Environmental Affairs and Tourism. Pretoria.

SNIJMAN. D. \& PERRY. P. 1987. A floristic analysis of the Nieuwoudtville Wild Flower Reserve, northwestem Cape. South African Joumal of Botany 53: 445-454.

TALJAARD. M.S. 1949. A glimpse of South Africa: 48. 49. University of Stellenbosch Publications.

TAYLOR. H.C. 1996. Cederberg vegetation and flora. Strelitzia 3. National Botanical Institute. Pretoria.

VAN WILGEN. B.W.. BOND. W.J. \& RICHARDSON, D.M. 1992 Ecosystem management. In R.M. Cowling. Ecology of finbos: nutrients, fire and diversity: Oxford University Press, Cape Town.

\section{APPENDIX}

List of species used in the classification, with their authors and families. Nomenclature from PRECIS (Arnold \& De Wet 1993) and authors of plant names from Brummitt \& Powell (1992).

\begin{tabular}{|c|c|c|c|}
\hline Species & Family & Species & Family \\
\hline Chrysocoma ciliata P.J.Bergius & Asteraceae & Ischyrolepis unispicata H.P.Linder & Restionaceae \\
\hline Diosma acmaeophylla $E c k l$ \& Zeyh. & Rutaceae & Leucadendron & Proteaceae \\
\hline Dodonaea angustifolia $L . f$ & Sapindaceae & bruniodes var. brunioides Meisn. & \\
\hline Dolichothrix ericoides (Lam.) Hilliard \& B.L.Burnt & Asteraceae & pubescens $R \cdot B r$. & \\
\hline Elytropappus rhinocerotis (L.f.) Less. & Asteraceae & Maytenus oleoides (Lam.) Loes. & Celastraceae \\
\hline Erica maximiliani Guthrie \& Bolus & Ericaceae & Phylica & Rhamnaceae \\
\hline $\begin{array}{l}\text { Eriocephalus } \\
\text { africanus } L\end{array}$ & Asteraceae & $\begin{array}{l}\text { buxifolia } L \text {. } \\
\text { odorata } S c h l t r .\end{array}$ & \\
\hline ericoides $(L f$.$) Druce$ & & Protea glabra Thunb. & Proteaceae \\
\hline $\begin{array}{l}\text { Euphorbia } \\
\text { decussata E.Mey. ex Boiss. } \\
\text { hamata (Haw.) Sweet }\end{array}$ & Euphorbiaceae & $\begin{array}{l}\text { Pteronia } \\
\text { divaricata (P.J.Bergius) Less. } \\
\text { incana (Burm.) DC. }\end{array}$ & Asteraceae \\
\hline mauritanica $L$ & & Rhus undulata Jacq. & Anacardiaceae \\
\hline Euryops & Asteraceae & Stipagrostis namaquensis (Nees) De Winter & Poaceae \\
\hline othonnoides ( $D C$. , B. Nord. & & Stoebe fusca $(L)$ Thunb. & Asteraceae \\
\hline wageneri Compton & & Tylecodon & Crassulaceae \\
\hline Felicia scabrida ( $D C$, ) Range & Asteraceae & paniculatus (Lf.) Toelken & \\
\hline Ficinia dunensis Levyns & Cyperaceae & wallichii (Han.) Toelken & \\
\hline Galenia africana $L$ & Aizoaceae & Willdenowia incurvata (Thunh.) H.P.Linder & Restionaceae \\
\hline Gnidia deserticola Gilg & Thymelaeaceae & Zygophyllum retrofractum Thunb. & Zygophyllaceae \\
\hline Hoplophyllum spinosum $D C$. & Asteraceae & & \\
\hline
\end{tabular}

